\title{
A Multi-Factor User Interface Components Layout Problem
}

Dinesh K. Sharma, University of Maryland Eastern Shore, Princess Anne, MD

S. K. Peer, K.S.R.M.College of Engineering, Cuddapah, India

Julius A. Alade, University of Maryland Eastern Shore, Princess Anne, MD

\begin{abstract}
This paper presents a multi-factor layout model which combines the qualitative and quantitative factors for the facilities layout problem. The proposed model is applied to the design of the user interface in order to obtain the best layout of the facilities in which the closeness rating scores are evaluated by using the Goals, Operators, Methods, and Selection (GOMS) technique. The results of the proposed model are compared with that of an existing model to obtain the layouts of user interface components. The model developed here has significant relevance for facility layout design in achieving an optimal interface by structuring the layout of a building to enhance and support production. The user interface model provides support for quick response to changes in customer demand and inventory planning particularly in such an area where timely transfer of information is crucial.
\end{abstract}

\subsection{Introduction}

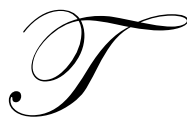

he system components and other devices by which human user and the system exchange inputs and outputs is known as the user interface. The user interface design is the overall design of the system components and other devices including their layouts by which human user and the system exchange inputs and outputs. The user interface components layout problem has the goal of locating the different components in order to achieve the greatest efficiency in exchanging the inputs and outputs between the human user and the system. The basic framework for the design of user interface including the layouts of its components is provided in Human-Computer Interaction (HCI) cognitive modeling (Card et al. 1983). Olson and Olson (1990) reviewed the state of the art of cognitive modeling in the GOMS (Goals, Operators, Methods, and Selection Rules) tradition, discussing several extensions to the basic framework. Previous studies have shown GOMS to be a powerful and accurate method of analysis for human performance (Bovair et al.1990). Later, GOMS was expanded to model tasks with low level perceptual, cognitive, and motor operators (John 1990). This opens up the possibility of using GOMS to compare different layouts, and used for the analysis of a single-objective layouts on key stroking or mouse pointing and graphic and textual layouts, etc. (Chuam et al.1994).

A single objective layout problem is formulated into quadratic assignment problem (QAP) with the objective of either maximization of the subjective qualitative closeness relationships or minimization of quantitative interactions between the pairs of components. In order to design the layout of the user interface components, the subjective closeness relationship ratings (A, E, I, O, U, and X) between the various pairs of components is used, with the objective of maximizing the closeness relationship score (McCormick et al. 1982). The closeness relationship ratings between the various pairs of components may possibly be evaluated by using the GOMS technique. There are different qualitative approaches developed for the design of the layouts. Seehof and Evans (1967), Lee and Moore (1967), and Muther and McPherson (1970) developed algorithms based on qualitative criteria to obtain the layouts.

These approaches are distinguished primarily by the scoring system for the closeness ratings, and consider only qualitative factor in the objective function. In order to design the layout of user interface components satisfying the principles: (1) Importance principle (2) Frequency-of-use principle (3) Functional principle, and (4) 
Sequence-of-use principle (McCormick et al. 1982), it is required that we turn to the multi-objective layout design of the components. Rosenblat (1979), Dutta and Sahu (1982), Fortenberry and Cox (1985), and Urban (1987) have presented a quadratic assignment formulations for the multi-objective layout problems. Each multi-goal approach uses a different scheme to assign numerical values to the relationship codes (A, E, I, O, U, and X) from the relationship charts.

This paper proposes a multi-factor layout model which combines the qualitative and quantitative factors for the facilities layout problem. The proposed model is applied to the design of the part of the user interface in order to obtain the best layout of the facilities. Finally, the results of the proposed model are compared with that of an existing model in the same manner to obtain the layouts of user interface components.

\subsection{Review Of Past Models}

The quadratic assignment formulation of the multi-objective layout problem is shown in equations (1) to

$$
\begin{aligned}
& \text { Minimize } \mathrm{Z}=\underset{\mathrm{i}}{\sum_{\mathrm{j}}} \sum_{\mathrm{j}}^{\mathrm{n}} \sum_{\mathrm{k}} \sum_{1} \mathrm{~A}_{\mathrm{ijkl}} \mathrm{x}_{\mathrm{ij}} \mathrm{x}_{\mathrm{kl}} \\
& \text { Subject to: } \quad \sum_{\mathrm{i}}^{\mathrm{n}} \mathrm{x}_{\mathrm{ij}}=1, \quad \mathrm{j}=1,2, \ldots, \mathrm{n} \\
& \qquad \sum_{\mathrm{j}}^{\mathrm{n}} \mathrm{x}_{\mathrm{ij}}=1, \quad \mathrm{i}=1,2, \ldots, \mathrm{n} \\
& \mathrm{x}_{\mathrm{ij}}=0 \text { or } 1, \forall \mathrm{i}, \mathrm{j}
\end{aligned}
$$

The variable $\mathrm{A}_{i j k l}$ is a cost variable representing the combination of qualitative and quantitative measures in multi-objective layout models. The various authors have presented different formulations for the cost term $\left(\mathrm{A}_{i j k l}\right)$. Equation (2) ensures that each location contains only one component and equation (3) ensures that each component is assigned to only one location.

One common characteristic of these multi-objective approaches is that they consider just two factors (or parameters) in the objective function formulation. The layouts of the user interface components obtained by using these approaches restrict the user to follow a unique set of procedures to accomplish a task. In order to design the layout of user interface components, which allows the user to execute a procedure of his/her own choice to accomplish a task, it is required to consider many numbers of factors, both qualitative and quantitative for the layout problem.

A solution procedure presented by Harmonosky and Tothero (1992) handles many numbers of qualitative and quantitative factors in the objective function in the same manner, i.e., assigning the same weight. Several different qualitative relationship charts may be used to represent different kinds of relationships. For example, the qualitative relationships between the pairs of components designed by different users of user interface may be 
considered separately. It is also possible to consider several quantitative aspects. For example, number of interactions between the pairs of components may vary from one user to another based on his skill and familiarity with the system. The methodology begins by combining individual factors, qualitative and quantitative alike, into a single composite factor for the objective function. First, all qualitative factors are quantified so that they may be handled mathematically. Second, all factors are normalized so that each will have an equivalent effect on the final layout. To normalize a factor, each value is divided by the sum of all values for that factor as given in equation (5).

$$
\mathrm{T}_{\mathrm{ikm}}=\mathrm{S}_{\mathrm{ikm}} / \sum_{\mathrm{i}}^{\mathrm{n}} \sum_{\mathrm{k}}^{\mathrm{n}} \mathrm{S}_{\mathrm{ikm}}
$$

Where, $S_{\mathrm{ikm}}=$ relationship value between facilities $\mathrm{i}$ and $\mathrm{k}$ for factor $\mathrm{m}$.

$$
\mathrm{R}_{\mathrm{ikp}}=\text { normalized relationship value when facilities } \mathrm{i} \text { and } \mathrm{k} \text { for factor } \mathrm{m} \text {. }
$$

Next, all values are multiplied by weights $\left(\alpha_{\mathrm{m}}\right)$ representing the relative importance of each factor $\mathrm{m}$. Finally, all factors are combined in to one composite factor $\left(\mathrm{A}_{i j k l}\right)$ as given in equation (6).

$$
\mathrm{A}_{\mathrm{ijkl}}=\sum_{\mathrm{m}=1}^{\mathrm{t}} \boldsymbol{\alpha}_{\mathrm{m}} \mathrm{T}_{\mathrm{ikm}} \mathrm{d}_{\mathrm{jl}}
$$

Where, $\mathrm{t}=$ number of factors and $\mathrm{d}_{\mathrm{jl}}=$ distance between locations $\mathrm{j}$ and $\mathrm{l}$.

Although, the cost term $\left(\mathrm{A}_{\mathrm{ijk}}\right)$ in the objective function of the model presented by Harmonosky and Tothero (1992) considered multi-goals or factors, both the qualitative and quantitative factors are treated alike. The effectiveness of multi-factor facilities layout method can be judged by treating the qualitative and quantitative factors separately. The layout methodology presented in this paper addresses the procedure to handle qualitative and quantitative factors separately. The methodology begins by combining all individual qualitative and quantitative factors into two separate qualitative and quantitative factors. The combined qualitative and quantitative factors are assigned weights based on their relative importance, and then combined into a single composite factor, which is solved by using construction or improvement procedures.

\subsection{Proposed Methodology}

First, several different relationship-charts may be used to represent different kinds of relationships. The closeness relationship ratings range from $\mathrm{A}$ to $\mathrm{X}$. These closeness relationship ratings for different factors are quantified so that they may be handled mathematically. These qualitative factors are normalized so that each will have an equivalent effect on the layout. To normalize a factor, each relationship value is divided by the sum of the relationship values for that factor as shown in equation (7).

$$
\mathrm{R}_{\mathrm{ikp}}=\mathrm{r}_{\mathrm{ikp}} / \sum_{\mathrm{i}}^{\mathrm{u}} \sum_{\mathrm{k}}^{\mathrm{u}} \mathrm{r}_{\mathrm{ikp}}
$$

Where, $\mathrm{r}_{\mathrm{ikp}}=$ relationship value between components $\mathrm{i}$ and $\mathrm{k}$ for factor $\mathrm{p}$.

$\mathrm{R}_{\mathrm{ikp}}=$ normalized relationship value between the components $\mathrm{i}$ and $\mathrm{k}$ for factor $\mathrm{p}$.

Next, weights $\left(\beta_{\mathrm{p}}\right)$ are applied to each factor as given in equation (8) so that the final layout appropriately reflects the relative importance of each qualitative factor. 


$$
\mathrm{R}_{\mathrm{ik}=} \sum_{\mathrm{p}=1}^{\mathrm{u}} \beta_{\mathrm{p}} \mathrm{R}_{\mathrm{ikp}}
$$

Where, $\quad \sum_{\mathrm{p}=1}^{\mathrm{u}} \beta_{\mathrm{p}}=1$

$$
\mathrm{u}=\text { number of qualitative factors. }
$$

Then, the total of all qualitative factor values for each pair of facilities is calculated to obtain the combined qualitative factor.

Second, it is possible to consider several quantitative aspects, since the interactions between the components may vary based on the skill of the user. Hence, the quantitative factor is characterized by interaction ranging from minimum to maximum limits. The interaction values may be obtained from a from-to-chart for different factors. Then, each quantitative factor (q) is normalized as shown in equation (9), so that each will have an equivalent effect on the layout.

$$
\mathrm{F}_{\mathrm{ikq}}=\mathrm{f}_{\mathrm{ikq}} / \sum_{\mathrm{i}}^{\mathrm{n}} \sum_{\mathrm{k}}^{\mathrm{n}} \mathrm{f}_{\mathrm{ikq}}
$$

Where, $\mathrm{f}_{\mathrm{ikq}}=$ number of interactions between components $\mathrm{i}$ and $\mathrm{k}$ for factor $\mathrm{q}$.

$\mathrm{F}_{\mathrm{ikq}}=$ normalized interactions value between components $\mathrm{i}$ and $\mathrm{k}$ for factor $\mathrm{q}$.

Next, weights $\left(\Upsilon_{\mathrm{q}}\right)$ are applied to each quantitative factor $(\mathrm{q})$ as given in equation (10) so that the final layout appropriately reflects the relative importance of each quantitative factor.

$$
\mathrm{B}_{\mathrm{ik}}=\sum_{\mathrm{q}=1}^{\mathrm{W}} \gamma_{\mathrm{q}} \mathrm{F}_{\mathrm{ikq}}
$$

$$
\begin{aligned}
& \text { Where, } \quad \begin{array}{l}
\sum_{\mathrm{q}=1}^{\mathrm{W}} \gamma_{\mathrm{q}}=1 \\
\mathrm{w}=\text { Number of quantitative factors. }
\end{array}
\end{aligned}
$$

The total of all quantitative factor values for each pair of components is calculated to obtain the combined quantitative factor.

Finally, the composite factor is obtained by combining the weighted combined qualitative and quantitative factors and then multiplying with distance $\left(\mathrm{d}_{\mathrm{jl}}\right)$ between locations $\mathrm{j}$ and 1 as shown in equation (11).

$$
A_{i j k l}=\left(W_{1} A_{i k}+W_{2} B_{i k}\right) d_{j l}
$$

Where, $\mathrm{W}_{1}, \mathrm{~W}_{2}$ are weights applied to combined qualitative and combined quantitative factors based on the importance of closeness relationships and the interactions between the components. This is expressed as:

$$
\mathrm{W}_{1}+\mathrm{W}_{2}=1 \text {, and } \mathrm{W}_{1}, \mathrm{~W}_{2} \geq 0
$$


The problem is formulated by substituting equation (11) for $A_{\mathrm{ijkl}}$ in equation (1). The resulting formulation is shown in equations (12) through (15).

$$
\begin{aligned}
& n \text { n } n \text { n } \\
& \operatorname{Maximize} \mathrm{Z}=\sum_{i=1} \sum_{j=1} \sum_{k=1} \sum_{l=1}\left(\mathrm{~W}_{1} \mathrm{~A}_{\mathrm{ik}}+\mathrm{W}_{2} \mathrm{~B}_{\mathrm{ik}}\right) \mathrm{d}_{\mathrm{jl}} \mathrm{x}_{\mathrm{ij}} \mathrm{x}_{\mathrm{kl}} \\
& \text { Subject to: } \quad \sum_{i=1}^{\mathrm{n}} \mathrm{x}_{i j}=1, \mathrm{j}=1,2, \ldots, \mathrm{n} \\
& \sum_{j=1}^{\mathrm{n}} \mathrm{x}_{i j}=1, \mathrm{i}=1,2, \ldots, \mathrm{n} \\
& \mathrm{x}_{i j}=0 \text { or } 1, \quad \forall \mathrm{i}, \mathrm{j} \\
& \text { Where, } \quad \mathrm{A}_{\mathrm{ik}}=\sum_{\mathrm{p}=1}^{\mathrm{u}} \beta_{\mathrm{q}} \mathrm{R}_{\mathrm{ikp}} \\
& \mathrm{B}_{\mathrm{ik}}=\sum_{\mathrm{p}=1}^{\mathrm{u}} \gamma_{\mathrm{q}} \quad \mathrm{F}_{\mathrm{ikp}}
\end{aligned}
$$$$
\mathrm{u}=\text { number of qualitative factors }
$$$$
\mathrm{w}=\text { number of quantitative factors }
$$$$
\mathrm{n}=\text { number of components }
$$$$
\mathrm{x}_{\mathrm{ij}}=\left\{\begin{array}{l}
1, \text { if component } \mathrm{i} \text { is assigned to location } \mathrm{j} \\
0, \text { other wise }
\end{array}\right.
$$

$\mathrm{i}$ and $\mathrm{k}$ are indices for components number and $\mathrm{j}$ and $\mathrm{l}$ are indices for location number.

It is possible to relax constraint (13) to have more locations available than number of facilities, in which some locations will be left vacant after the layout is complete, and equation (13) can be replaced with equation (16), where $r$ is the number of possible locations.

$$
\sum_{\mathrm{i}=1}^{\mathrm{n}} \mathrm{x}_{\mathrm{iv}} \leq 1, \mathrm{v}=1,2, \ldots, \mathrm{r}
$$

Once composite relationship or cost term $\mathrm{A}_{\mathrm{ijkl}}$ has been calculated, the problem is solved as a single factor problem, which may be solved by either construction or improvement procedures.

The following application to design the layout of user interface components illustrates the proposed methodology.

\subsection{An Application}

In explaining the methodologies used to design the layout of the user interface components, we have adapted from the study by John and Kieras, (1996b) a text edited in MS-WORD as a task example. The text is considered as component 1 and it is required to be modified by deleting the strike-off characters. This process brings 
rounded phrase to the location indicated by an arrow, setting the text to have right justification, and spell checking as shown in the example task. In order to accomplish these tasks, the user interface components to be used are Del, Cut, Paste, Right, and Spell Check, and these are numbered as components 2, 3, 4, 5, and 6 respectively. The rating system used for the qualitative closeness relationships between the various pairs of components is: $\mathrm{A}=5, \mathrm{E}=4, \mathrm{I}=$ $3, \mathrm{O}=2, \mathrm{U}=1$, and $\mathrm{X}=0$. The GOMS technique is expected to evaluate the subjective qualitative relationships between the various pairs of components. The quantitative factor is characterized as the interactions between the various pairs of components. The interaction between he pair of components is defined as the use of one component immediately after another component to perform an operation. It is assumed that the interactions are ranging from 1 to 4 for the task under consideration.

The qualitative closeness relationship ratings evaluated by using GOMS techniques, the quantitative interactions between the various pairs of components $i$ and $k$ for 3 users, and the distance $\left(\mathrm{d}_{j l}\right)$ between the location $j$ and $l$ are given in Table 1 (See Appendix).

Figure 1: Example Task: Editing a Marked-Up Manuscript

\section{In order to understand GOMS models that have}

arisen in the last decade and the relationships them,

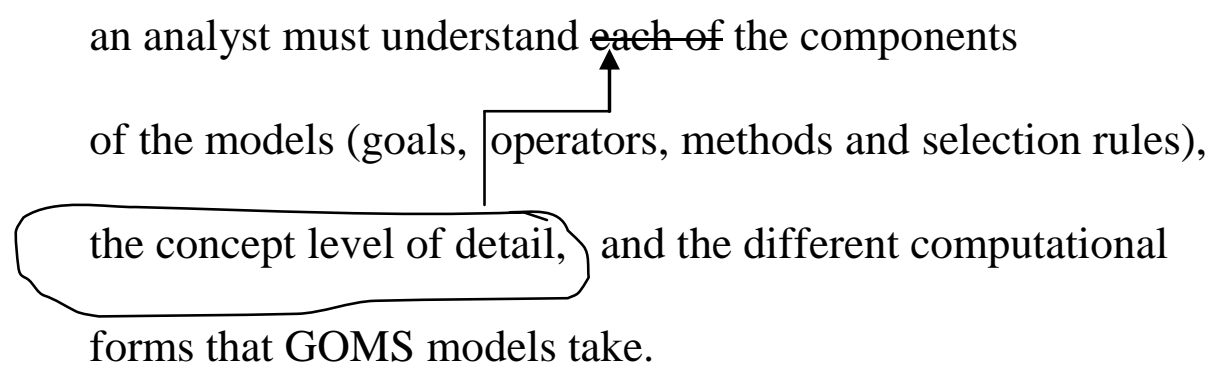

Source: Adapted from John and Kieras, 1996b.

Each factor is assigned with weight so that the final layout of the component (facility) reflects the relative importance of each factor. For the proposed methodology, each of 3 qualitative factors is assigned with weights $\beta_{1}=0.2, \beta_{2}=0.5$, and $\beta_{3}=0.3$, such that

3 $\sum_{\mathrm{p}=1} \beta_{\mathrm{p}}=1$, and each of 3 quantitative factors is assigned with weights $\Upsilon_{1}=0.4, \Upsilon_{2}=0.3$, and $\Upsilon_{3}=0.3$, such that $\sum_{\mathrm{q}=1}^{3} \gamma_{\mathrm{q}}=1$. For the Haromonosky and Tothero $(\mathrm{H}$ and $\mathrm{T})$ model, since both qualitative and quantitative factors are handled in same manner, each of 6 factors is assumed to be assigned with weights $\alpha_{1}=0.2, \alpha_{2}=0.1, \alpha_{3}=0.15, \alpha_{4}=0.25, \alpha_{5}=0.1$, and $\alpha_{6}=0.2$, such

that $\sum_{\mathrm{m}=1}^{6} \alpha_{\mathrm{m}}=1$. 


\section{$H$ and $T$ method}

The composite closeness relations steps by using $\mathrm{H}$ and $\mathrm{T}$ model for the data given in Table 1 (See Appendix) are obtained as follows.

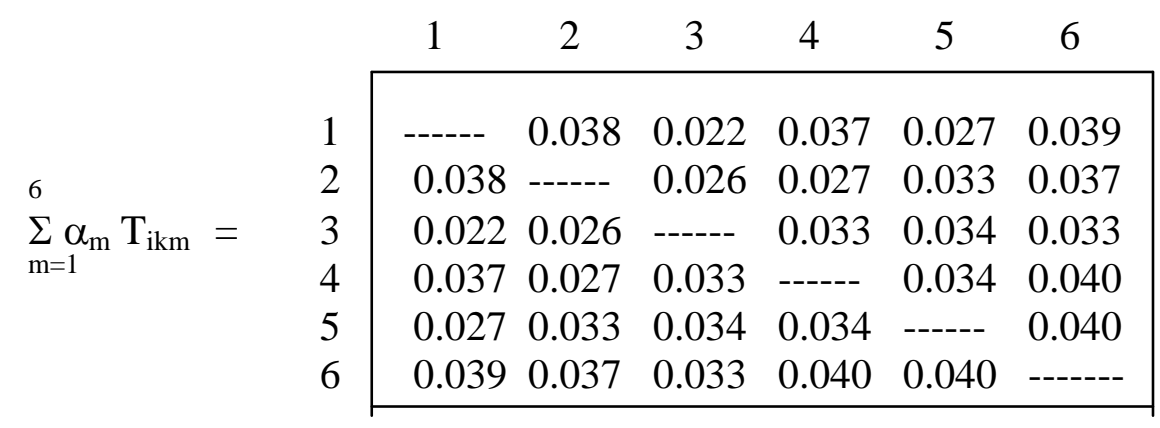

\begin{tabular}{|c|c|c|c|c|c|c|}
\hline & 1 & 2 & 3 & 4 & 5 & 6 \\
\hline 1 & - & 3 & 6 & 3 & 5 & 7 \\
\hline 2 & 3 & - & 3 & 5 & 3 & 5 \\
\hline 3 & 6 & 3 & - & 8 & 6 & 3 \\
\hline $\mathrm{d}_{\mathrm{jl}}=4$ & 3 & 5 & 8 & - & 3 & 6 \\
\hline 5 & 5 & 3 & 6 & 3 & - & 3 \\
\hline 6 & 7 & 5 & 3 & 6 & 3 & \\
\hline
\end{tabular}

The layouts and their scores by using $\mathrm{H}$ and $\mathrm{T}$ methodology are obtained as follows.

Construction Heuristic

Layout

\begin{tabular}{|l|l|l|}
\hline 2 & 3 & 4 \\
\hline 6 & 1 & 5 \\
\hline
\end{tabular}

Score

2.354

\section{Pair-wise Exchange Heuristic \% Improvement}

Layout

\begin{tabular}{|l|l|l|}
\hline 3 & 1 & 4 \\
\hline 6 & 2 & 5 \\
\hline
\end{tabular}

Score

2.320

1.44

The combined qualitative factor $\left(A_{i k}\right)$, combined quantitative factor $\left(B_{i k}\right)$, and the composite factor $\left(W_{1} A_{i k}+W_{2} B_{i k}\right)$ obtained by using the proposed method for the weights $\mathrm{W}_{1}=0.2$, and $\mathrm{W}_{2}=0.8$ are given as follows. 


\section{Proposed Method}

\begin{tabular}{cl|cccccc}
\multicolumn{1}{c}{} & \multicolumn{1}{c}{1} & 2 & 3 & 4 & 5 & 6 \\
\cline { 3 - 8 } $\mathrm{A}_{\mathrm{ik}}=$ & 1 & ------ & 0.033 & 0.024 & 0.035 & 0.028 & 0.038 \\
& 2 & 0.033 & ------ & 0.038 & 0.025 & 0.019 & 0.045 \\
& 3 & 0.024 & 0.038 & ----- & 0.035 & 0.019 & 0.046 \\
& 4 & 0.035 & 0.025 & 0.035 & ------ & 0.042 & 0.046 \\
& 5 & 0.025 & 0.019 & 0.019 & 0.042 & ------ & 0.035 \\
\hline & 0.038 & 0.045 & 0.046 & 0.046 & 0.035 & ------ \\
\hline
\end{tabular}

\begin{tabular}{rl|cccccc}
\multicolumn{1}{c}{} & \multicolumn{1}{c}{1} & 2 & 3 & 4 & 5 & 6 \\
\cline { 3 - 8 } & 1 & - & 0.038 & 0.016 & 0.037 & 0.033 & 0.035 \\
$\mathrm{~B}_{\mathrm{ik}}=$ & 2 & 0.038 & ----- & 0.029 & 0.027 & 0.048 & 0.032 \\
& 3 & 0.016 & 0.029 & ----- & 0.031 & 0.033 & 0.028 \\
& 4 & 0.037 & 0.027 & 0.031 & ------ & 0.029 & 0.040 \\
& 5 & 0.033 & 0.048 & 0.033 & 0.029 & ------ & 0.038 \\
& 6 & 0.035 & 0.032 & 0.028 & 0.040 & 0.038 & ------ \\
\hline
\end{tabular}

\begin{tabular}{|c|c|c|c|c|c|c|}
\hline & 1 & 2 & 3 & 4 & 5 & 6 \\
\hline \multirow{6}{*}{$0.2 \mathrm{~A}_{\mathrm{ik}}+0.08 \mathrm{~B}_{\mathrm{ik}}=$} & ----- & 0.037 & 0.018 & 0.037 & 0.032 & 0.036 \\
\hline & 0.037 & ------ & 0.031 & 0.027 & 0.042 & 0.035 \\
\hline & 0.018 & 0.031 & ------ & 0.032 & 0.030 & 0.032 \\
\hline & 0.037 & 0.027 & 0.032 & ------ & 0.032 & 0.041 \\
\hline & 0.032 & 0.042 & 0.030 & 0.032 & ------ & 0.037 \\
\hline & 0.036 & 0.035 & 0.032 & 0.041 & 0.037 & ------ \\
\hline
\end{tabular}

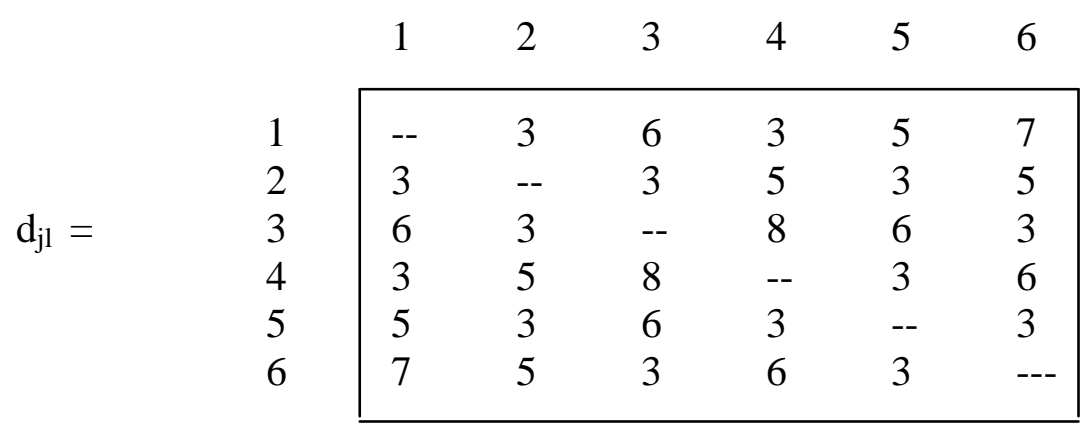

The layouts and scores obtained by using the proposed method for $\mathrm{W}_{1}=0.2, \mathrm{~W}_{2}=0.8$ are given as follows. 


\section{Construction Heuristic}

Layout
\begin{tabular}{|l|l|l|}
\hline 2 & 3 & 6 \\
\hline 1 & 4 & 5 \\
\hline
\end{tabular}

\section{\% Improvement} over H \& T model
Pair-wise Exchange Heuristic

\% Improvement

\begin{tabular}{|c|c|c|c|}
\hline Score & & & \\
\hline 210 & 140 & & 6 \\
\hline & & & 4 \\
\hline
\end{tabular}

Score

2.282

1.60

The results of the proposed methodology for different weights $\left(\mathrm{W}_{1}\right.$ and $\left.\mathrm{W}_{2}\right)$ assigned to the combined qualitative $\left(\mathrm{A}_{\mathrm{ik}}\right)$ and the combined quantitative $\left(\mathrm{B}_{\mathrm{ik}}\right)$ factors respectively are given in Table 2 for the data given Table 1 .

It is observed from table 2 that the solution obtained by proposed model is improved by an average $2.48 \%$ over $\mathrm{H}$ and $\mathrm{T}$ model. Similarly, it is observed that the solution of the proposed method is improved by an average 2.30 percent by the pair wise exchange heuristic. The computational experiences have shown that the methodology is easy to understand and the results obtained are of practically acceptable quality, since the qualitative and quantitative factors are handled in different manner. The methodologies can also be extended to judge whether the keys (facilities) in the keyboard are located at their right locations. Also, in this case, closeness relationship charts between the pairs of facilities are to be developed by using GOMS techniques for different factors.

\subsection{Conclusion}

In this paper we have presented a methodology, which handles multiple factors, both qualitative and quantitative, for the design of the layout of the components of the user interface. The qualitative relationship ratings between the various pairs of components of user interface are evaluated by using the GOMS technique. The proposed methodology handles qualitative and quantitative factors in different manner, and their results are compared with that of an existing Haramonsky and Tothero (1992) method in which the qualitative and quantitative factors are handled in the same manner. From the results, it is observed that the solution obtained by using the proposed methodology is improved over Haramonsky and Tothero (1992) method, and also improved by using the pair-wise exchange heuristic. Since the proposed methodology handles the qualitative and quantitative factors in different manner, the results are practically acceptable quality for real life problems.

The study has important application to facility layouts both in manufacturing and service sectors of operations management. The solutions to the component layout seek to achieve an optimal interface of the facilities, equipment, and personnel that make up the operations management system. By designing a multi-factor user interface that minimizes the loss time between components layout, the model provide a solution to operations management that enhances the performance of personnel in their job tasks. As pointed out by Lee and Schniederjans, (1994), by structuring the layout of a building to enhance and support production, operations managers can greatly improve the efficiency of their service or manufacturing system. The study is also significant to the application of timely transfer of inventory information to achieve quick response to changes in customer demand and inventory planning. In a broader overview, the user interface components layout problem has application to other areas like flexible manufacturing layout system (FMS), computer integrated manufacturing system (CIMS), the use of artificial intelligence and expert system, and electronic shopping and service system that permits customers to place orders for items or receive customer service from remote service facilities.

\section{References}

1. Bovair, S., Kieras, D.E., and Polson, P.G. (1990). "The acquisition and performance of text editor skill: A Cognitive complexity analysis". Human computer Interaction, 5, pp 1-48.

2. Card, S.K., Moran, T.P., and Newell, A. (1983). "The Psychology of Human - Computer Interaction". Lawrence Erlbaum, Hillsdale, N.J.

3. Chuam, M.C., John, B.E., and Pane, J. (1994). "Analysing graphic and textual layouts with GOMS. Results of a Preliminary analysis". In proceedings companion of CHI'94. ACM, New York, 1994, pp 323-324. 
4. Dutta, K.N. and Sahu, S. (1982). "A multi-goal heuristic for facilities design problem: MUGHAL". International Journal of Production Research, Vol.20, No.2, 1982, pp 147-154.

5. Fortenberry, J.F., and Cox, J.S. (1985). "Multiple criteria approach to the facilities layout problem", International journal of production Research. Vol. 23, No. 4, pp 773-782.

6. Harmonosky, C.M., and Tothero, G.K. (1992). "A multi-factor plant layout methodology", International journal of production Research. Vol.30, No.8, pp 1773-1789.

7. John. B., (1990). "Extension of GOMs analysis to expert performance requiring perception of dynamic visual; and auditory information". In CHI'90 proceedings, (Seattle, W.A). ACM: NY, pp 107-115.

8. John, B.E. and Kieras, D.E (1996a). "Using GOMS for user interface design and evaluation: which Techniques". ACM Trans. Computer-Human Interactions, Vol. 3, No. 4, pp 287-319.

9. John, B.E., and Kieras, D.E (1996b). "The GOMS family of analysis techniques comparison and contrast", ACM Trans. Computer-Human Interactions, Vol. 3, No. 4, pp 320-351.

10. Lee, R.C., and Moore, J.M. (1967). "CORELAP - Computerized relationship layout planning", Journal of Industrial Engineering, 18, PP: 195-200.

11. Lee, S.M. and Schniederjans (1994). Operations Management. Houghton Mifflin Company, Boston.

12. Mc Cormick, E.J., Marks, S., and Sanders (1982). "Human Factors in Engineering Design", Tata Mcgraw-Hill, $1982,5^{\text {th }}$ edn. New Delhi.

13. Muther, R., and Mc Pherson, K. (1970). "Four approaches to computerized layout planning", Industrial Engineering, 21, pp 39-42.

14. Olson, J.R., and Olson, G.M., (1990). "The Growth of Cognitive Modeling in Human - Computer Interaction since GOMS". Human-Computer Interaction Vol. 5, pp 221-265.

15. Rosenblatt, M.J. (1979). "The facilities layout problem: A multi-goal approach". International journal of production Research. Vol.17, No.4, pp 323-332.

Seehof, J.M. and Evans, W.O. (1967). "Automated layout design problem". The journal of Industrial Engineering, 18, pp 690-695.

16. Urban, T.L. (1987). "A Multiple Criteria Model for the Facilities Layout Problem". International Journal of Production Research, Vol. 25, No.12, pp 1805-1812. 


\section{APPENDIX}

Table 1: 6 - Components (facilities) problem data.

\begin{tabular}{|c|c|c|c|c|c|c|c|c|c|c|}
\hline \multicolumn{2}{|c|}{ Components } & \multicolumn{3}{|c|}{$\begin{array}{l}\text { Qualitative } \\
\text { Factors }\end{array}$} & \multicolumn{3}{|c|}{$\begin{array}{c}\text { Quantitative } \\
\text { Factors }\end{array}$} & \multicolumn{3}{|c|}{$\begin{array}{l}\text { Distances between } \\
\text { Locations } \\
j \quad \text { and } l\end{array}$} \\
\hline$i$ & $k$ & 1 & 2 & 3 & 1 & 2 & 3 & $j$ & $i$ & $d_{j l}$ \\
\hline 1 & 2 & 4 & 3 & 2 & 3 & 2 & 4 & 1 & 2 & 3 \\
\hline 1 & 3 & 2 & 1 & 4 & 1 & 1 & 3 & 1 & 3 & 6 \\
\hline 1 & 4 & 3 & 2 & 5 & 2 & 4 & 2 & 1 & 4 & 3 \\
\hline 1 & 5 & 1 & 4 & 1 & 4 & 2 & 1 & 1 & 5 & 5 \\
\hline 1 & 6 & 5 & 3 & 3 & 3 & 3 & 2 & 1 & 6 & 7 \\
\hline 2 & 1 & 4 & 3 & 2 & 3 & 2 & 4 & 2 & 1 & 3 \\
\hline 2 & 3 & 0 & 5 & 3 & 2 & 3 & 2 & 2 & 3 & 3 \\
\hline 2 & 4 & 3 & 2 & 2 & 3 & 2 & 1 & 2 & 4 & 5 \\
\hline 2 & 5 & 1 & 4 & 0 & 4 & 3 & 4 & 2 & 5 & 3 \\
\hline 2 & 6 & 4 & 3 & 4 & 1 & 4 & 3 & 2 & 6 & 5 \\
\hline 3 & 1 & 2 & 1 & 4 & 1 & 1 & 2 & 3 & 1 & 6 \\
\hline 3 & 2 & 0 & 5 & 3 & 2 & 3 & 2 & 3 & 2 & 3 \\
\hline 3 & 4 & 2 & 3 & 4 & 3 & 1 & 3 & 3 & 4 & 8 \\
\hline 3 & 5 & 5 & 0 & 2 & 2 & 2 & 4 & 3 & 5 & 6 \\
\hline 3 & 6 & 3 & 4 & 5 & 1 & 4 & 2 & 3 & 6 & 3 \\
\hline 4 & 1 & 3 & 2 & 5 & 2 & 4 & 3 & 4 & 1 & 3 \\
\hline 4 & 2 & 3 & 2 & 2 & 3 & 2 & 1 & 4 & 2 & 5 \\
\hline 4 & 3 & 2 & 3 & 4 & 3 & 1 & 3 & 4 & 3 & 8 \\
\hline 4 & 5 & 4 & 4 & 3 & 2 & 3 & 2 & 4 & 5 & 3 \\
\hline 4 & 6 & 2 & 5 & 4 & 4 & 2 & 3 & 4 & 6 & 6 \\
\hline 5 & 1 & 1 & 4 & 1 & 4 & 2 & 1 & 5 & 1 & 5 \\
\hline 5 & 2 & 1 & 3 & 0 & 4 & 3 & 4 & 5 & 2 & 3 \\
\hline 5 & 3 & 5 & 0 & 2 & 2 & 2 & 4 & 5 & 3 & 6 \\
\hline 5 & 4 & 4 & 4 & 3 & 2 & 3 & 2 & 5 & 4 & 3 \\
\hline 5 & 6 & 3 & 2 & 5 & 3 & 2 & 4 & 5 & 6 & 3 \\
\hline 6 & 1 & 5 & 3 & 3 & 3 & 3 & 2 & 6 & 1 & 7 \\
\hline 6 & 2 & 4 & 4 & 4 & 1 & 4 & 3 & 6 & 2 & 5 \\
\hline 6 & 3 & 3 & 4 & 5 & 1 & 4 & 2 & 6 & 3 & 3 \\
\hline 6 & 4 & 2 & 5 & 4 & 4 & 2 & 3 & 6 & 4 & 6 \\
\hline 6 & 5 & 3 & 2 & 5 & 3 & 2 & 4 & 6 & 5 & 3 \\
\hline
\end{tabular}


Table 2: Results of proposed methodology: Area limited to 2 rows and 3 columns.

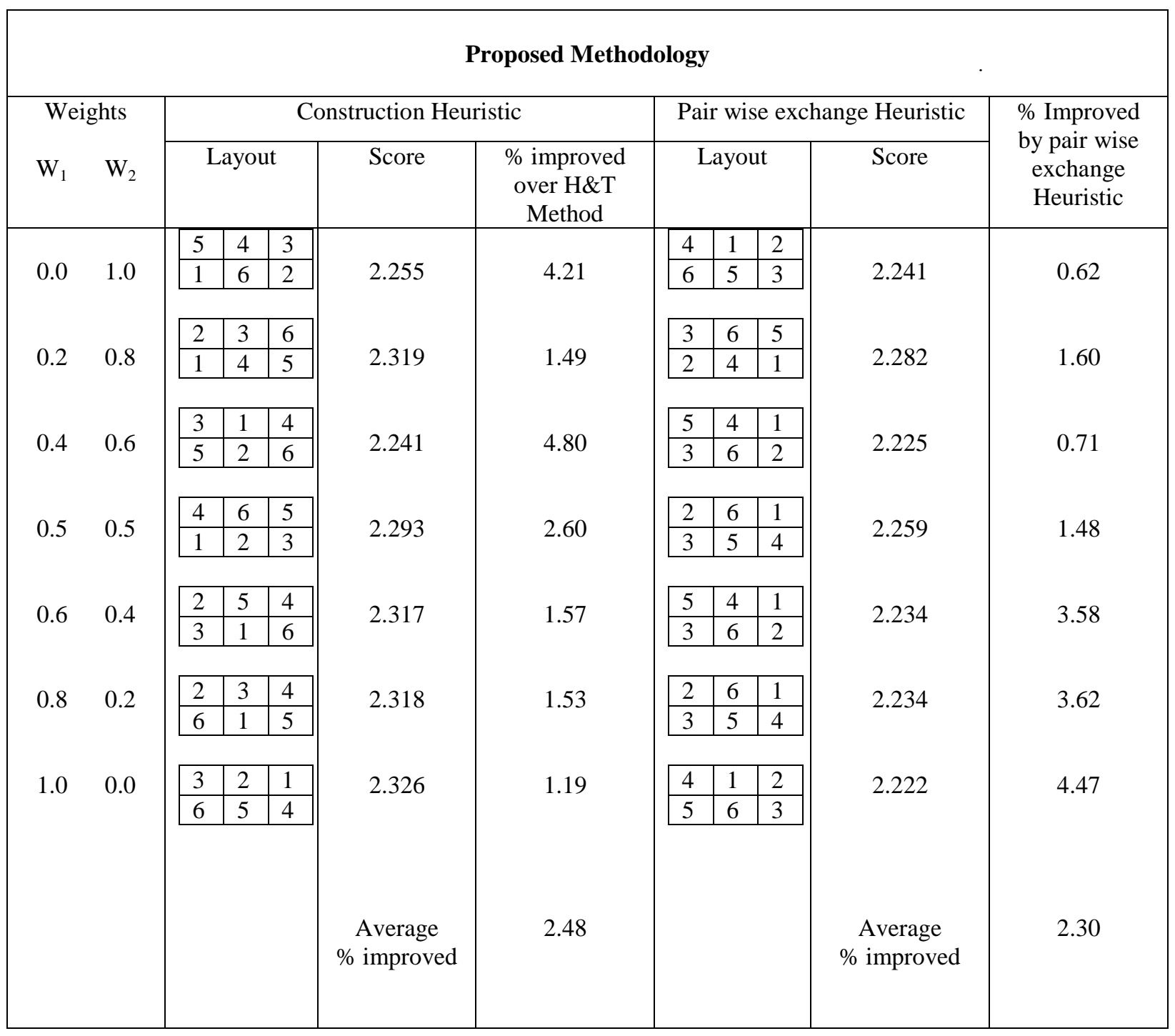

